\title{
Dissolution of basaltic glass in natural wetlands of Iceland
}

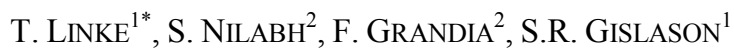

${ }^{1}$ Institute of Earth Scinces, University of Iceland, Sturlugata

7,101 Reykjavik, Iceland (*correspondence: tol5@hi.is)

${ }^{2}$ Amphos 21 Consulting SL, Carrer de Veneçuela 103, 08019

Barcelona, Spain

Basaltic glass dissolution is an important part of weathering processes in the ocean and on land and affects the global carbon cycle. The dissolution of basaltic glass under laboratory conditions has been well described by several authors, e.g. Oelkers and Gislason [1]. Nevertheless, natural processes are typically more complex and not well characterized.

We investigated the dissolution of basaltic glass $\left(\mathrm{SiAl}_{0.35} \mathrm{Fe}_{0.19} \mathrm{Mg}_{0.28} \mathrm{Ca}_{0.26} \mathrm{Na}_{0.08} \mathrm{O}_{3.37}\right.$ [1]) and organic as well as inorganic carbon storage in a natural wetland environment under subarctic oceanic climate. For that purpose, in situ soil water samplers were installed at various depths within the soil and samples were filtrated and stabilized before analysis. The charge balance, chemical speciation and saturation stage with respect to the primary and secondary phases were assessed with the PHREEQC code and the minteq.v4 database [2]. A 1-D reaction path model based on PHREEQC and COMSOL Multiphysics ${ }^{\circledR}$ was then compiled to interpret the field observations.

Chemical analysis of soil water from different horizons show an increase of $\mathrm{Si}, \mathrm{Mg}, \mathrm{Ca}, \mathrm{Fe}$ and $\mathrm{Mn}$ with depth, whereas Al concentrations are 100x lower than expected, indicating a low Al mobility. Reduced species of Fe and Mn are dominating deep inside the soil, but are more oxidized at shallower level, indicating a significant oxidation gradient and mineral precipitation.

Reactive transport modelling suggests the supersaturation of poorly crystalline aluminium silicate clays, ferrihydrite and $\mathrm{SiO}_{2}$, which are characteristic for these soils. Furthermore, the formation of siderite $\mathrm{FeCO}_{3}$ seems to be possible under these conditions and was proven by field observations.

The main processes can be summarized as dissolution of basaltic glass by oxic rainwater, decomposition of organic matter and precipitation of secondary minerals such as aluminium silicate clays and iron minerals including ferrihydrite and siderite.

[1] Oelkers, E. and Gislason, S.R. (2001): Geochim. Cosmochim. Acta 65, 3671-3681.

[2] Parkhurst, D.L. and Appelo, C.A.J. (2013): U.S. Geological Survey Techniques and Methods, book 6, chap. A43, 497 p. 